(C) 2022, The Authors. Published by Elsevier Inc. and Fass Inc. on behalf of the American Dairy Science Association ${ }^{\circledR}$. This is an open access article under the CC BY license (http://creativecommons.org/licenses/by/4.0/).

\title{
Effect of bupivacaine liposome suspension administered as a cornual nerve block on indicators of pain and distress during and after cautery dehorning in dairy calves
}

\author{
Miriam S. Martin, ${ }^{1} \oplus$ Michael D. Kleinhenz, ${ }^{2 *} \oplus$ Abbie V. Viscardi, ${ }^{1}$ Andrew K. Curtis, ${ }^{1} \oplus$ Blaine T. Johnson, ${ }^{3} \oplus$ \\ Shawnee R. Montgomery, ${ }^{1}$ () Maria E. Lou, ${ }^{1}$ () and Johann F. Coetzee ${ }^{1 *}$ () \\ ${ }^{1}$ Department of Anatomy and Physiology, College of Veterinary Medicine, Kansas State University, Manhattan 66506 \\ ${ }^{2}$ Department of Clinical Sciences, College of Veterinary Medicine, Kansas State University, Manhattan 66506 \\ ${ }^{3}$ Department of Diagnostic Medicine and Pathobiology, College of Veterinary Medicine, Kansas State University, Manhattan 66506
}

\begin{abstract}
Dehorning is performed on a high percentage of dairies worldwide. Concern about the negative effect of dehorning on animal welfare has contributed to the development of new guidelines that require the use of pain management at the time of disbudding in the United States. However, livestock producers are limited in how to address this requirement due to a lack of (1) approved analgesic drugs, (2) analgesic options that control pain for an extended duration, and (3) analgesic formulations that are practical for producers to administer. The objective of this study was to evaluate the effectiveness of bupivacaine liposome suspension, a novel, long-acting, local anesthetic formulation administered as a nerve block at dehorning, compared with current industry standard analgesic approaches using lidocaine nerve blocks alone or in combination with the nonsteroidal anti-inflammatory drug meloxicam. Fifty male Holstein calves, 10 to 14 wk of age, were enrolled and randomly assigned to 1 of 5 treatment groups before cautery dehorning as follows: (1) bupivacaine liposome suspension block, oral placebo (BUP); (2) lidocaine block, oral placebo (LID); (3) lidocaine block, oral meloxicam $(1 \mathrm{mg} / \mathrm{kg}$ of body weight; LID + MEL); (4) saline block, oral placebo (CON); and (5) saline block, oral placebo, sham dehorn (SHAM). Biomarkers were collected from 0 to $120 \mathrm{~h}$ postdehorning and included infrared thermography, mechanical nociceptive threshold (MNT), pressure mat gait analysis, chute defense and behavior scoring, and blood sampling for serum cortisol and prostaglandin $\mathrm{E}_{2}$ metabolites. Responses were analyzed using repeated measures with calf nested in treatment designated as a random effect,
\end{abstract}

\footnotetext{
Received July 13, 2021.

Accepted October 12, 2021.

*Corresponding authors: mkleinhe@vet.k-state.edu and jcoetzee@ vet.k-state.edu
}

and treatment, time, and their interaction designated as fixed effects. At $2 \mathrm{~h}$ postdehorning, the BUP group had a higher MNT compared with the CON group. Furthermore, at $24 \mathrm{~h}$ postdehorning, the BUP group had a higher MNT compared with the LID group. Gait distance differed significantly between treatment groups; the CON, LID, and LID + MEL groups had an increased gait distance relative to the SHAM group. The CON group exhibited a higher chute defense behavior score during the dehorning procedure compared with all other treatments. Furthermore, the CON group exhibited more ear flicks than the BUP and LID + MEL groups postdehorning. At $4 \mathrm{~h}$ and $24 \mathrm{~h}$ after dehorning, the LID + MEL group had a lower average prostaglandin $\mathrm{E}_{2}$ metabolites concentration compared with all other treatment groups. These data showed that administration of bupivacaine liposome suspension as a cornual nerve block at the time of dehorning was as effective at controlling pain as a multimodal approach of lidocaine and meloxicam.

Key words: analgesia, cattle, dehorning, pain

\section{INTRODUCTION}

Dehorning or disbudding is a routine management procedure performed on a high percentage of dairies in the United States, with the majority of calves being dehorned by 12 wk of age using a hot-iron (Fulwider et al., 2008; USDA-APHIS-NAHMS, 2018). Even when the procedure is performed in calves less than $4 \mathrm{wk}$ old, hot-iron dehorning causes behavioral, physiological, and neuroendocrine changes and a physical form of restraint is still required (Faulkner and Weary, 2000; Stock et al., 2013). Hot-iron dehorning causes an initial increase in cortisol concentrations that correspond to the acute pain of tissue damage and stress of restraint, which does not return to baseline levels for at least $24 \mathrm{~h}$ after the procedure, indicating the presence of a prolonged inflammatory response (Stafford and Mel- 
lor, 2005; Heinrich et al., 2009). Following burn injury, edema forms in the interstitial space rapidly for the first $8 \mathrm{~h}$, and then continues to form more slowly. This excessive or prolonged edema can exacerbate pain and impair wound healing (Rowan et al., 2015). There is no evidence indicating that farm animals are unable to experience pain (Viñuela-Fernández et al., 2007), and Mellor and Stafford (2004) suggest that newborn and young animals may experience pain more intensely than older animals.

Concerns about the negative effect of dehorning on animal welfare has contributed to the development of new guidelines in the United States that require the use of pain management at the time of disbudding (National Milk Producers Federation, 2020). The American Veterinary Medical Association recommends that pre-emptive analgesia be used to mitigate pain from dehorning procedures (AVMA, 2014), and the American Association of Bovine Practitioners recommends that pain management be the standard of care to mitigate pain from the dehorning procedure itself and the during the recovery and healing period (AABP, 2019). However, less than $15 \%$ of US producers report always using local anesthesia or analgesia at the time of disbudding in calves $<2$ mo of age (Johnstone et al., 2021). In a survey of European farms, pain relief for disbudding was only used on $<30 \%$ of farms (Cozzi et al., 2015). In an Ontario survey, $97 \%$ of veterinarians and $62 \%$ of producers reported using a local anesthetic, and $48 \%$ of veterinarians and $24 \%$ of producers used a nonsteroidal anti-inflammatory drug (NSAID) for disbudding or dehorning (Winder et al., 2016). One factor contributing to the low adoption rate of pain mitigation protocols on US farms is the lack of US Food and Drug Administration (FDA)-approved analgesic drugs (Robles et al., 2021). In a survey published in $2021,89.5 \%$ of US veterinarians reported that federal regulations limit their ability to use analgesic drugs (Johnstone et al., 2021). Moreover, 50\% of respondents attributed a reduction in their analgesic use to concern about administering drugs that lack FDA approval. However, as the American Association of Bovine Practitioners recommends in their dehorning guidelines (AABP, 2019), veterinarians are permitted to prescribe analgesic drugs for extralabel purposes under the Animal Medicinal Use Clarification Act of 1994 (FDA, 1994). Other factors contributing to the low adoption of pain mitigation protocols include a lack of analgesic options that control pain for an extended duration and a lack of analgesic formulations that are practical for producers to administer. Globally, whether pain control is mandatory for disbudding or dehorning based on regulations or program enrollment, along with analgesic drug availability, has led to a wide disparity in accepted standard practices.

A multimodal approach using local anesthetics and NSAID is recommended as the most effective method for reducing pain in cattle following dehorning (Stock et al., 2013; Winder et al., 2018). In many instances, a solution that has both rapid onset and prolonged duration of analgesia is optimal. Lidocaine, the original amino-amide local anesthetic that is most widely used in veterinary practice, has a limited duration of action (20-40 $\mathrm{min}$ ), and bupivacaine, which is among the most potent and long-acting of the amino-amides with a higher pKa value than lidocaine, has a longer duration of action $(5-8 \mathrm{~h})$ but is thought to have a later onset (30 min; Best et al., 2015; Riviere and Papich, 2018). McMeekan et al. (1998) administered bupivacaine 20 min before dehorning and again a second time $4 \mathrm{~h}$ after the procedure and prevented a cortisol response for $8 \mathrm{~h}$; yet, the feasibility of administering a local anesthetic twice must be taken into consideration. A novel extended-release liposomal formulation of bupivacaine was approved for dogs in 2016 and cats in 2018, with administration before surgery providing up to $72 \mathrm{~h}$ of pain control (FDA, 2016, 2018). Liposomal bupivacaine has been shown to have an increased duration of action and a delayed peak plasma concentration when compared with bupivacaine hydrochloride (Tong et al., 2014). Meloxicam is an NSAID with preferential cyclooxygenase-2 activity (Smith, 2013) that is a practical analgesic option for producers due to its long half-life of $27 \mathrm{~h}$ (Coetzee et al., 2009). Meloxicam has not been shown to mitigate signs of acute distress (Coetzee et al., 2012) but has been shown to reduce the prolonged stress response in calves following dehorning (Allen et al., 2013). The objective of this study was to evaluate the effectiveness of bupivacaine liposome suspension, a novel, long-acting, local anesthetic formulation administered as a nerve block at dehorning, against current industry standard analgesic approaches predicated on using lidocaine nerve blocks alone, or in combination with the NSAID meloxicam.

\section{MATERIALS AND METHODS}

\section{Animals, Housing, and Treatments}

The Kansas State University Institutional Animal Care and Use Committee reviewed and approved the experimental protocol for this project (IACUC\# 4259). This study was conducted at the Kansas State University College of Veterinary Medicine in Manhattan, Kansas, in July and August 2020. Pain was anticipated for calves in the control group as a result of dehorn- 
ing. All calves were assessed 3 times daily for signs of excessive pain via behavior, as well as inappetence for a 120-h period after the procedure. A rescue analgesic protocol for administration of flunixin meglumine $(2.2$ $\mathrm{mg} / \mathrm{kg}$ of BW, i.v., every $12 \mathrm{~h}$ ) was in place if calves showed excessive lying, reluctance to rise, or inappetence following dehorning. A total of 50 male Holstein calves that were all weaned, vaccinated, horned, and intact were received for potential enrollment onto the study in June 2020.

Calves were group housed in outdoor pens with open front run-in sheds of equal size for shelter. Pens had concrete flooring bedded with straw and were of size exceeding the guidelines for the Guide for Care and Use of Agricultural Animals in Research and Teaching (FASS, 2020). Calves were fed a grain diet formulated at $3.5 \% \mathrm{BW}$ twice daily per normal procedures at the study site along with free choice hay. Calves were moved to the study site upon arrival and were given a 2 -wk acclimation period; throughout the acclimation period, calves were trained to be led with a halter and stand haltered for an extended period of time to facilitate biomarker collection.

After the acclimation period, before the start of the study, calves were weighed and averaged $92 \mathrm{~kg}$ (range: $67-117 \mathrm{~kg}$ ). Calves were 10 to $14 \mathrm{wk}$ of age at the time of enrollment. Calves were randomly allocated to 1 of 5 experimental treatment groups and were cautery dehorned in randomly allocated groups of 10 for feasibility. Randomization was accomplished using the RAND function in Microsoft Excel (Microsoft Excel 2016, Microsoft Corporation). The treatment groups were as follows: (1) bupivacaine liposome suspension block, oral placebo (BUP); (2) lidocaine block, oral placebo (LID); (3) lidocaine block, oral meloxicam (1 mg/kg of BW; LID + MEL); (4) saline block, oral placebo (CON); and (5) saline block, oral placebo, sham dehorn (SHAM). Ten calves were assigned to each treatment group, and 2 calves from each treatment group were assigned to each dehorning day (dehorning d 1,2, 3, 4, or 5 ), so each treatment was equally represented on each dehorning day. Calf was the experimental unit for the study. The duration of each dehorning phase was 120 $\mathrm{h}$, with baseline measures collected $24 \mathrm{~h}$ before calves being dehorned. The time of dehorning was considered the $0 \mathrm{~h}$ time point.

Calves were administered their treatment $10 \mathrm{~min}$ before the dehorning procedure. The local anesthetic block for dehorning consisted of a conventional cornual nerve block and a local block of the horn. For the cornual nerve block, 4 to $5 \mathrm{~mL}$ of local anesthetic was injected half-way between the lateral canthus of the eye and horn just ventral to the frontal crest on each side of the head. For the local block of the horn, as described in Bates et al. (2019), $1 \mathrm{~mL}$ of local anesthetic was injected laterally and caudally to the horn (12-14 $\mathrm{mL}$ total volume injected). At $5 \mathrm{~min}$ before dehorning, the local anesthetic block was tested by pricking the skin immediately adjacent to the horn with a hypodermic needle. If the animal responded to the needle stick (i.e., not anesthetized), the local anesthetic block was repeated. Calves were dehorned using a pre-heated (approximately $600^{\circ} \mathrm{C}$ ) propane dehorner (The Coburn Company, Inc.) placed on the horn tissue for approximately 15 to $20 \mathrm{~s}$ per horn. The sham dehorning procedure was the same as described for the dehorning procedure, except the dehorning iron was inactive (i.e., not turned on). The oral meloxicam tablets (Zydus Pharmaceuticals Inc.) were placed in a gelatin capsule (Torpac Inc.) and were administered via a bolus gun at a dosage of $1 \mathrm{mg} / \mathrm{kg}$ of BW. The oral placebo was lactose monohydrate powder (Thermo Fisher Scientific), which is the binder used in meloxicam tablets and was also placed in a gelatin capsule (Torpac Inc.) and administered via a bolus gun.

\section{Measurements and Sample Collection}

Outcome variables were collected at $-24,0,0.5,1,2$, $4,8,24,72$, and $120 \mathrm{~h}$ posttreatment, with chute defense behavior being scored at $0 \mathrm{~h}$ (at the time of dehorning) and pressure mat gait analysis beginning at $4 \mathrm{~h}$. Outcome variables collected included infrared thermography (IRT), mechanical nociceptive threshold (MNT), gait analysis using a pressure mat, chute defense and behavior scoring, and blood sampling for serum cortisol and prostaglandin $\mathrm{E}_{2}$ metabolites (PGEM; Figure 1). All trained personnel that collected outcome variables and scored behavior were masked to treatment for the duration of the study.

Blood samples for serum cortisol and PGEM determination were collected from the jugular vein via venipuncture. The whole-blood samples were immediately transferred to tubes (Vacutainer, BD Diagnostics) containing either no additive or EDTA anticoagulant for cortisol and PGEM determination, respectively. Blood samples were then centrifuged for $10 \mathrm{~min}$ at $3,000 \times g$ at $4^{\circ} \mathrm{C}$, and collected serum and plasma were placed in cryovials via transfer pipette and stored at $-80^{\circ} \mathrm{C}$.

\section{Infrared Thermography}

The IRT images captured the medial canthus of the left eye using a research-grade infrared camera (Fluke TiX580, Fluke Corp.) using methods adapted from (Kleinhenz et al., 2017). Infrared images were analyzed 


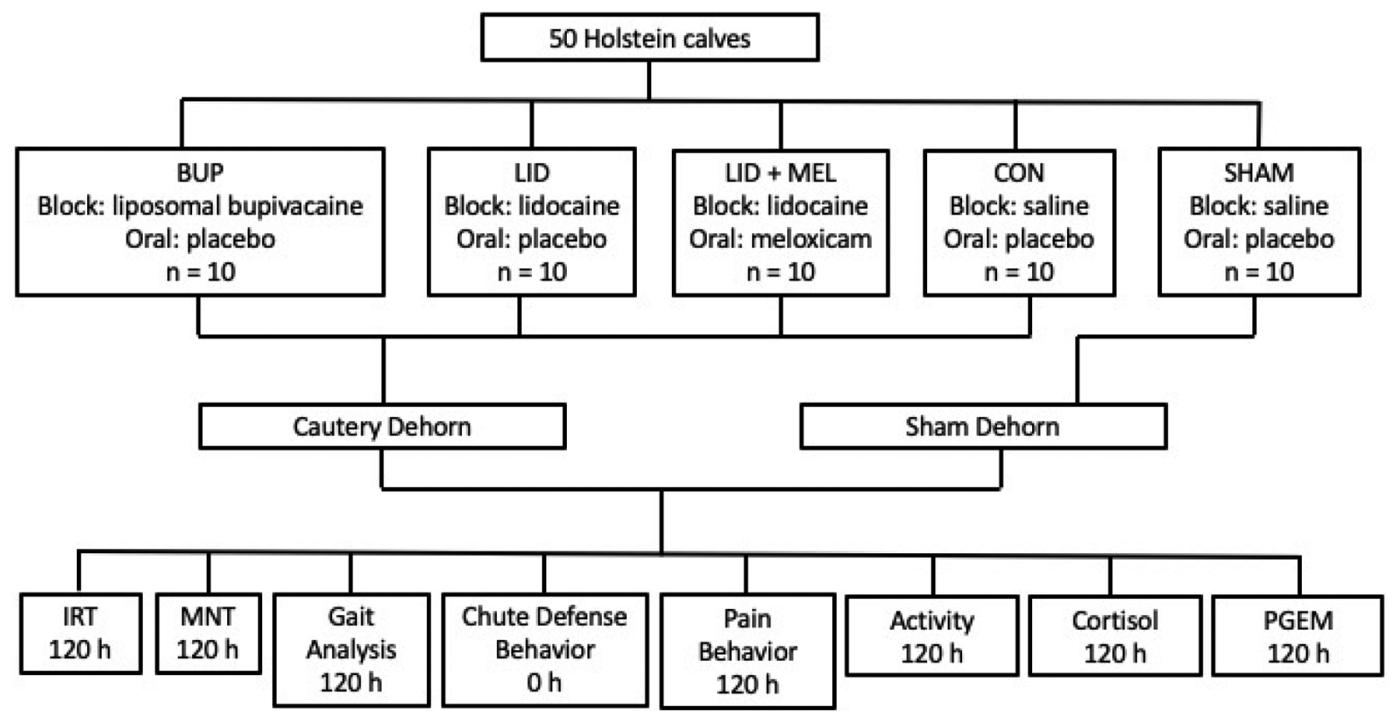

Figure 1. Flowchart outlining the timing of study events. Calves were dehorned and outcome variables were collected for the duration of time expressed in $\mathrm{h}(0-120)$ below each specific outcome variable. IRT = infrared thermography; MNT = mechanical nociceptive threshold; PGEM $=$ prostaglandin $\mathrm{E}_{2}$ metabolites.

using research-specific computer software (SmartView v. 4.3, Fluke Thermography) to determine maximum and minimum temperatures.

\section{Mechanical Nociceptive Threshold}

A hand-held pressure algometer (Wagner Instruments) was used for MNT determination using methods adapted from (Kleinhenz et al., 2017). A force was applied perpendicularly at a rate of approximately 1 $\mathrm{kg}$ of force (kgf) per second at 5 locations, consisting of 2 points ( 1 laterally and 1 caudally) around each horn at the hair-horn junction and a point in the center of the forehead. A withdrawal response was indicated by an overt movement away from the applied pressure algometer. The calves were blindfolded to prevent any sudden movements, and MNT values were recorded by a second investigator to prevent bias by the investigator performing the MNT collection.

\section{Pressure Mat Gait Analysis}

A commercially available pressure mat gait analysis system (Strideway, Tekscan, Inc.) was used to record gait and biomechanical parameters. The mat was placed next to the chute area so that calves could be dehorned, bio samples could be collected, and then calves could be immediately walked across the mat. The pressure mat was calibrated, using a known mass, to ensure accuracy of the measurements at each time point. Video synchronization was used to ensure consistent gait between and within calves at each time point. Using research-specific software (Strideway 7.7, Tekscan, Inc.), force, contact pressure, impulse, stance time, stride length, and gait distance were assessed.

\section{Behavior}

Chute defense behavior was scored at the time of dehorning using the scale adapted from (Grandin, 1993), also cited by Hoppe et al. (2010), summarized as (1) calm, no movement; (2) restless, shifting; (3) squirming, occasionally shaking of the chute; (4) continuous vigorous movement and shaking of the chute; and (5) rearing, twisting of the body, or violent struggling.

Video cameras (Sony Handycam HDR-CX405, Sony Corporation of America) were placed outside of the chute area or calf pens, based on the location of calves at each time point. Calves were video recorded the day before the dehorning procedure for $30 \mathrm{~min}$ to collect baseline behavior data. Postdehorning, calves were video recorded for $30 \mathrm{~min}$ at the following time points: 0 , $1,2,4,8$, and $24 \mathrm{~h}$. A random-number generator (random.org) to randomize the videos across time point and calf identification. Four observers masked to treatment, time point, and the research question used a detailed ethogram (Table 1) and BORIS software (Behavioral Observation Research Interactive Software v 7.7.3) to score calf behavior. Focal-animal continuous sampling was used for behavioral analysis. Pain behaviors (ear flicking, head shaking, head rubbing, tail flicking, and foot stamping) were classified as events, and the occur- 
Table 1. Ethogram used to score calf behavior [adapted from Heinrich et al. (2010) and Sutherland et al. (2013)]

\begin{tabular}{ll}
\hline Behavior & Description \\
\hline Eating & Ingesting food provided at feed bunk \\
Drinking & Consuming water from bucket or waterer \\
Ruminating & Regurgitating, chewing, and swallowing food \\
Grooming & Calf moves tongue over body, licking \\
Walking & Moving forward at a normal pace \\
Standing & Calf is upright and all 4 hooves are in contact with the ground \\
Lying & Calf is recumbent, body is in contact with the ground \\
Ear flicking & Calf rapidly moves one or both ears to the front and back, independent of head shaking \\
Head shaking & Calf rapidly shakes head from one side to the other \\
Head rubbing & Calf lifts hind leg to scratch top of head with foot or rubs head against sides of the pen or gate \\
Tail flicking & Calf rapidly moves tail from side to side; may include multiple tail movements within one tail-flicking event. A new tail- \\
Foot stamping & flicking event occurs after the tail moves slowly or is in a resting position \\
\hline
\end{tabular}

rence of each behavior (i.e., count data) was collected. The remaining behaviors in the ethogram were classified as states and total duration (s) of these behaviors across the observation period were collected. A total of $10,500 \mathrm{~min}(175 \mathrm{~h})$ of behavior recordings were scored and analyzed for this study. The interclass correlation coefficient for the interobserver reliability between the 4 individuals was calculated using data collected by having all observers score the same calf in 3 different videos for $30 \mathrm{~min}$. The interclass correlation coefficient was $\leq 0.9$ between the 4 individuals, indicating excellent reliability between observers.

\section{Cortisol}

Serum cortisol concentrations were determined using a commercially available radioimmunoassay kit (MP Biomedicals) following manufacturer specifications with minor modifications. The standard curve was extended to include 1 and $3 \mathrm{ng} / \mathrm{mL}$ by diluting the 10 and 30 $\mathrm{ng} / \mathrm{mL}$ manufacturer-supplied standards 1:10, respectively. The standard curve ranged from 1 to $300 \mathrm{ng} /$ $\mathrm{mL}$. We ran a low $(25 \mathrm{ng} / \mathrm{mL})$ and high $(150 \mathrm{ng} / \mathrm{mL})$ quality control at the beginning and end of each set to determine interassay variability. Plain $12 \times 75 \mathrm{~mm}$ polypropylene tubes were used as blank tubes to calculate nonspecific binding. Input for standards, quality controls, and samples was adjusted to $50 \mu \mathrm{L}$. Samples were incubated at room temperature for $30 \mathrm{~min}$ before the addition of I-125. Manufacturer instructions were then followed. Tubes were counted on a gamma counter (Wizard2, PerkinElmer) for $1 \mathrm{~min}$. The raw data file was then uploaded onto MyAssays Desktop software (version 7.0.211.1238) for concentration determination. Standard curves were plotted as a 4-parameter logistic curve. Samples with a coefficient of variation $(\mathbf{C V})>$ $18 \%$ were re-analyzed. The project average for serum cortisol intra-assay CV was $20.95 \%$, and interassay CV was $20.81 \%$.

\section{Prostaglandin $E_{2}$ Metabolites}

Prostaglandin $\mathrm{E}_{2}$ metabolites were analyzed using a commercially available ELISA kit (cat. no. 514531, Cayman Chemical) following manufacturer specifications with minor modifications. Sample input was adjusted to $375 \mu \mathrm{L}$ with $1.5 \mathrm{~mL}$ of ice-cold acetone added for sample purification. Samples were incubated at $-20^{\circ} \mathrm{C}$ for $30 \mathrm{~min}$., then centrifuged at $3,000 \times g$ for $5 \mathrm{~min}$ at room temperature $\left(\sim 20^{\circ} \mathrm{C}\right)$. Supernatant was transferred to clean $13 \times 100 \mathrm{~mm}$ glass tubes and evaporated using a CentriVap Concentrator (cat. no. 7810014, Labconco) overnight ( $\sim 18$ h). Samples were reconstituted with $375 \mu \mathrm{L}$ of appropriate kit buffer. A $300-\mu \mathrm{L}$ aliquot of the reconstituted sample was derivatized with proportionally adjusted kit components. Manufacturer protocol was then followed. Samples were diluted 1:2 and ran in duplicate. Absorbance was measured at $405 \mathrm{~nm}$ after $60 \mathrm{~min}$ of development (SpectraMax i3, Molecular Devices). Sample results were excluded if the raw read exceeded the raw read of the highest standard (standard $1 ; 50 \mathrm{pg} / \mathrm{mL}$ ) or was below the lowest acceptable standard. The lowest acceptable standard was defined for each individual plate and was identified by excluding standards that had a ratio of absorbance of that standard to the maximum binding of any well of $\geq 80 \%$ or $\leq 20 \%$. Any individual sample outside the standard curve, with a ratio of absorbance of that standard to the maximum binding of any well outside the 20 to $80 \%$ range, or a CV $>15 \%$, were reanalyzed. The project average for PGEM intra-assay CV was $15.08 \%$ and interassay CV was $11.40 \%$.

\section{Calculations and Statistical Analysis}

Mechanical nociceptive threshold was used to determine the number of calves needed per treatment group, as previously described (Heinrich et al., 2010). The study was designed to have power exceeding 0.80 , assuming 
a difference in effect size $(\Delta)$ of 0.51 , a standard error $(\sigma)$ of 0.13 , and a statistical inference level $(\alpha)$ of 0.05 . Based on this calculation, a sample size of 10 animals per treatment group was determined. Concentrations of serum cortisol and PGEM were log-transformed for normality before statistical analysis. Responses (i.e., IRT, MNT, gait analysis, behavior, serum cortisol, and PGEM) were analyzed using repeated measures with calf as the experimental unit. Calves nested in a treatment group were designated as a random effect, with treatment, time, and treatment by time interaction designated as fixed effects. F-tests were used for testing significance of main effects and interactions. If significant overall differences were identified, pairwise comparisons were performed using the Tukey honestly significant difference test. Statistics were performed using statistical software (JMP Pro 15.1.0 and Statistical Analysis System 9.4, SAS Institute, Inc.). Statistical significance was set a priori at $P \leq 0.05$. Data are presented as least squares means.

\section{RESULTS}

At 5 min before dehorning, after testing the local anesthetic block by pricking the skin immediately adjacent to the horn with a hypodermic needle, one instance of the calf responding was reported. The entire local anesthetic block was repeated on both horns (12-14 $\mathrm{mL}$ administered), and the calf was dehorned $10 \mathrm{~min}$ later after not responding to the needle prick following the second administration of the local anesthetic block. The calf was assigned to the BUP treatment group.

\section{Infrared Thermography}

A total of 498 IRT images were scored, and 2 images did not save properly to the IRT camera. No evidence was found for a treatment effect on IRT maximum ocular temperature $(P=0.72)$. The treatment groups had similar maximum ocular temperatures (Table 2). There was a significant time effect $(P<0.0001)$ with the highest ocular temperatures at $8 \mathrm{~h}\left(41.21^{\circ} \mathrm{C} ; 95 \%\right.$ CI: 40.79-41.63) being consistent with higher ambient temperatures midday. The lowest ocular temperatures $\left(29.34^{\circ} \mathrm{C} ; 95 \%\right.$ CI: $\left.28.60-30.09\right)$ were recorded at $120 \mathrm{~h}$.

\section{Mechanical Nociceptive Threshold}

A total of 1,750 MNT readings were recorded with 350 readings taken at each of 5 locations. There was evidence of a significant treatment by time interaction for mean MNT (kgf; $P<0.0001$; Table 2; Figure 2). At $2 \mathrm{~h}$, the BUP group (1.41 kgf: 95\% CI: 1.19-1.62) was less sensitive to force compared with the CON group
(0.88 kgf: 95\% CI: 0.67-1.10; $P=0.0009)$. At $24 \mathrm{~h}$, the BUP group (1.17 kgf: $95 \%$ CI: $0.95-1.38)$ was less sensitive to force compared with the LID group (0.81 kgf: $95 \%$ CI: $0.59-1.02 ; P=0.0201)$.

\section{Pressure Mat Gait Analysis}

A total of 6,578 data points were collected for gait analysis with 60 data points missing due to one failure to record along with calves not having an adequate number of full strides recorded. Gait distance $(\mathrm{cm})$ differed significantly between treatment groups $(P=$ 0.04); the CON, LID, and LID + MEL groups had an increased gait distance relative to the SHAM group (CON: $200.59 \mathrm{~cm} ; 95 \%$ CI: 191.17-210.02, LID 199.54 cm; 95\% CI: 190.05-209.03, LID + MEL $195.78 \mathrm{~cm}$; 95\% CI: 186.35-205.20, SHAM $182.10 \mathrm{~cm} ; 95 \%$ CI: 172.63-191.48; Table 2; Figure 3). There was a significant treatment by time interaction for mean stance time (s; $P<0.0001$; Table 1$)$. There was no evidence of a treatment effect for mean stride $(\mathrm{cm} ; P=0.31)$, mean force $(\mathrm{kg} ; P=0.9499)$, mean impulse $(\mathrm{kg} \times \mathrm{s} ; P$ $=0.38)$, or mean pressure $\left(\mathrm{kg} / \mathrm{cm}^{2} ; P=0.18\right.$; Table 2$)$.

\section{Behavior}

For the behavior data, 3,560 observations were collected, and 1,845 were used for analysis due to calves being out of view. Calves were partially or fully obstructed from view and with $41 \pm 16 \%$ (SE) of the scoring period unavailable for scoring. There was evidence of a treatment effect for mean chute defense behavior score $(P<0.0001$; Table 3 ; Figure 4$)$. The CON group (CON score 4.7) exhibited a significantly higher mean chute defense behavior score relative to all other treatment groups (LID score 3.3, $P=0.005$; BUP score 2.4, $P<0.0001 ;$ LID + MEL score $2.4, P<0.0001 ;$ SHAM score 1.6, $P<0.0001)$. Additionally, the LID group exhibited a significantly higher mean chute defense behavior score relative to the SHAM group $(P=0.007)$.

Drinking behavior differed by treatment $(P=0.03$; Table 3; Figure 5). The BUP group spent significantly more time drinking across the observation period compared with the LID + MEL $(P=0.03)$ group. Eating behavior demonstrated a significant time effect $(P<$ 0.0001). Calves spent significantly less time eating at $4 \mathrm{~h}$ (estimate: $-1,103.65, P<0.0001), 8 \mathrm{~h}$ (estimate: -904.06, $P=0.01$ ), and $24 \mathrm{~h}$ (estimate: $-619.51, P$ $=0.001$ ) compared with baseline measures at $-24 \mathrm{~h}$. There was no evidence of a treatment effect for eating $(P=0.55)$, grooming $(P=0.64)$, lying $(P=0.54)$, ruminating $(P=0.66)$, standing $(P=0.66)$, or walking $(P=0.30)$ activities (Table 2$)$. 
Martin et al.: LIPOSOMAL BUPIVACAINE ANALGESIAAT DEHORNING

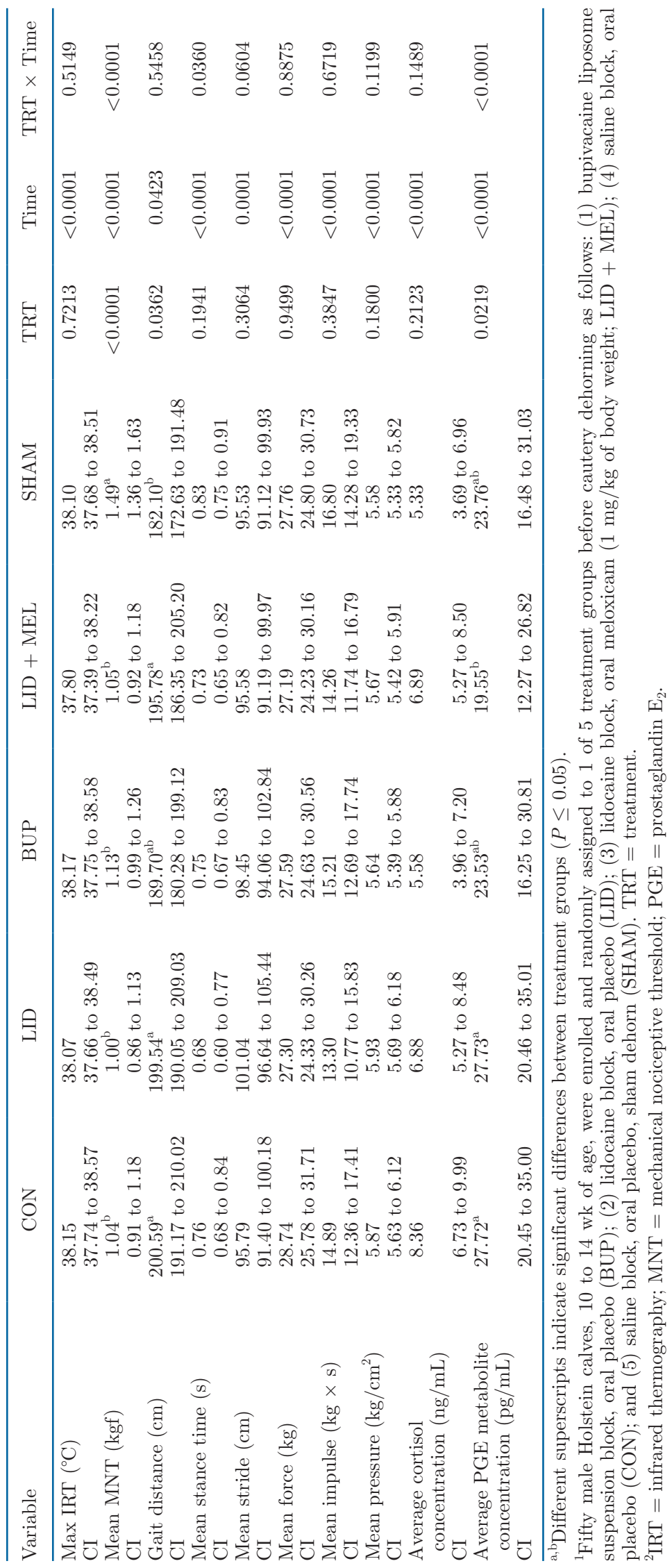


Ear flicking differed significantly by treatment $(P=$ 0.002; Table 3; Figure 6). The CON group flicked their ears significantly more than the BUP $(P=0.01)$ and LID + MEL $(P=0.002)$ groups. There was no evidence of a treatment effect for the pain behaviors tail flicking $(P=0.17)$, foot stamping $(P=0.64)$, head rubbing $(P$ $=0.19)$, or head shaking $(P=0.10$; Table 3$)$.

\section{Cortisol}

A total of 442 data points were reported for cortisol concentrations due to 58 samples collected not having detectable cortisol concentrations. No evidence of a treatment effect was found for average cortisol concentrations $(\mathrm{ng} / \mathrm{mL})$ when log-transformed $(P=$ 0.21 ). The treatment groups had similar overall average cortisol concentrations (Table 2; Figure 7). There was a significant time effect observed $(P<0.0001)$ with average concentrations being highest at $0 \mathrm{~h}(14.47 \mathrm{ng} /$

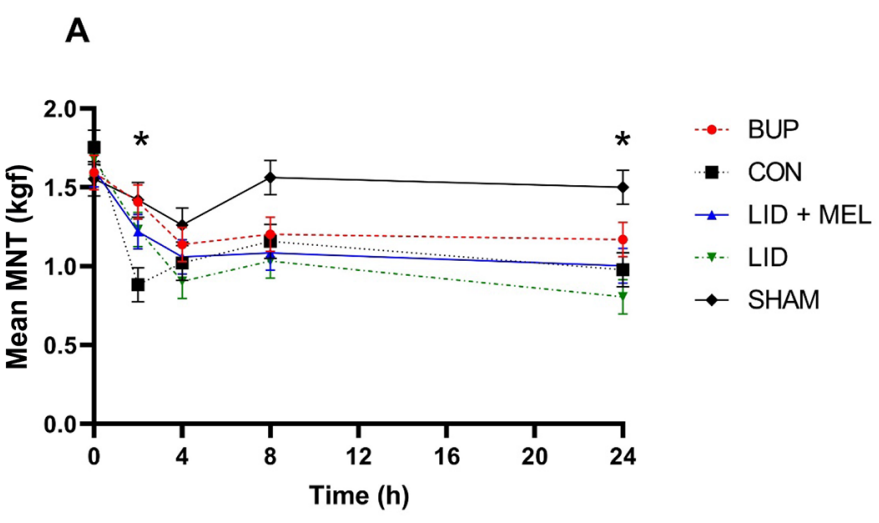

B

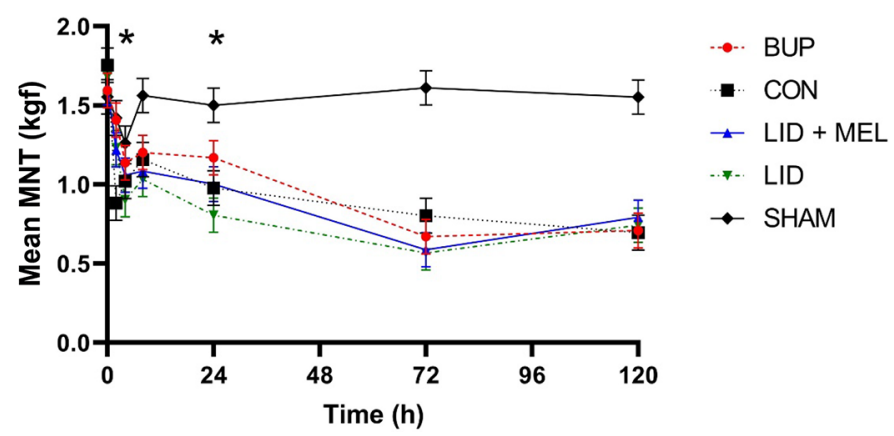

Figure 2. Mean mechanical nociceptive threshold values measured in $\mathrm{kg}$ of force (kgf) over the first $24 \mathrm{~h}$ of the study (A) and for the study duration (B) for each of the 5 treatment groups. Error bars indicate SEM. *Denotes time points where a significant difference $(P \leq$ 0.05 ) was observed between at least 2 treatment groups. BUP $=$ bupivacaine liposome suspension block, oral placebo; $\mathrm{CON}=$ saline block, oral placebo; LID + MEL = lidocaine block, oral meloxicam; LID = lidocaine block, oral placebo; SHAM = saline block, oral placebo, sham.

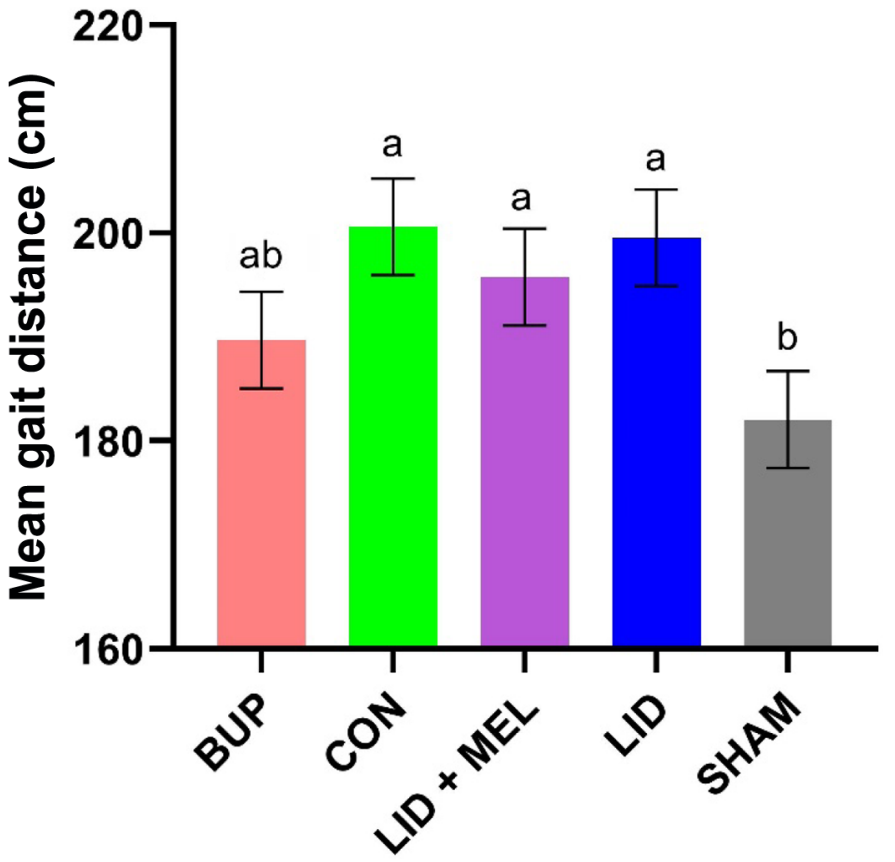

Figure 3. Mean gait distance values measured in $\mathrm{cm}$ via pressure mat gait analysis for the duration of the study $(120 \mathrm{~h})$ for each of the 5 treatment groups. Error bars indicate SEM. Different letters $(\mathrm{a}, \mathrm{b})$ indicate significant differences between treatment groups $(P \leq 0.05)$. $\mathrm{BUP}=$ bupivacaine liposome suspension block, oral placebo; $\mathrm{CON}=$ saline block, oral placebo; LID + MEL = lidocaine block, oral meloxicam; LID = lidocaine block, oral placebo; SHAM = saline block, oral placebo, sham.

$\mathrm{mL} ; 95 \%$ CI: $13.14-15.80)$ and $0.5 \mathrm{~h}(15.36 \mathrm{ng} / \mathrm{mL}$; 95\% CI: 14.04-16.70).

\section{Prostaglandin $E_{2}$ Metabolites}

A total of 250 PGEM samples were collected and analyzed, and their concentrations reported. There was evidence of a significant treatment by time interaction for average PGEM concentrations $(\mathrm{pg} / \mathrm{mL})$ following log-transformation $(P<0.0001$; Table 2 ; Figure 8$)$. At $4 \mathrm{~h}$, the LID + MEL group had a lower average PGEM concentration (15.19 pg/mL: 95\% CI: 6.05-24.33) compared with all other treatment groups (LID: $28.73 \mathrm{pg} /$ mL; 95\% CI: 19.59-37.86, BUP: $23.81 \mathrm{pg} / \mathrm{mL} ; 95 \%$ CI: 14.67-32.95, CON: $23.85 \mathrm{pg} / \mathrm{mL}$; 95\% CI: $14.72-32.99$, SHAM: $23.51 \mathrm{pg} / \mathrm{mL} ; 95 \%$ CI: $14.37-32.65 ; \quad P<$ $0.0001)$. At $24 \mathrm{~h}$, the LID + MEL group had a lower average PGEM concentration $(10.63 \mathrm{pg} / \mathrm{mL}$ : $95 \%$ CI: 1.49-19.77) compared with all other treatment groups (LID: $24.74 \mathrm{pg} / \mathrm{mL} ; 95 \%$ CI: 15.61-33.88, BUP: 17.61 $\mathrm{pg} / \mathrm{mL} ; 95 \%$ CI: 8.47-26.74, CON: $30.17 \mathrm{pg} / \mathrm{mL} ; 95 \%$ CI: 21.03-39.30, SHAM: $24.19 \mathrm{pg} / \mathrm{mL} ; 95 \%$ CI: $15.05-$ 33.32; $P<0.0001)$. 


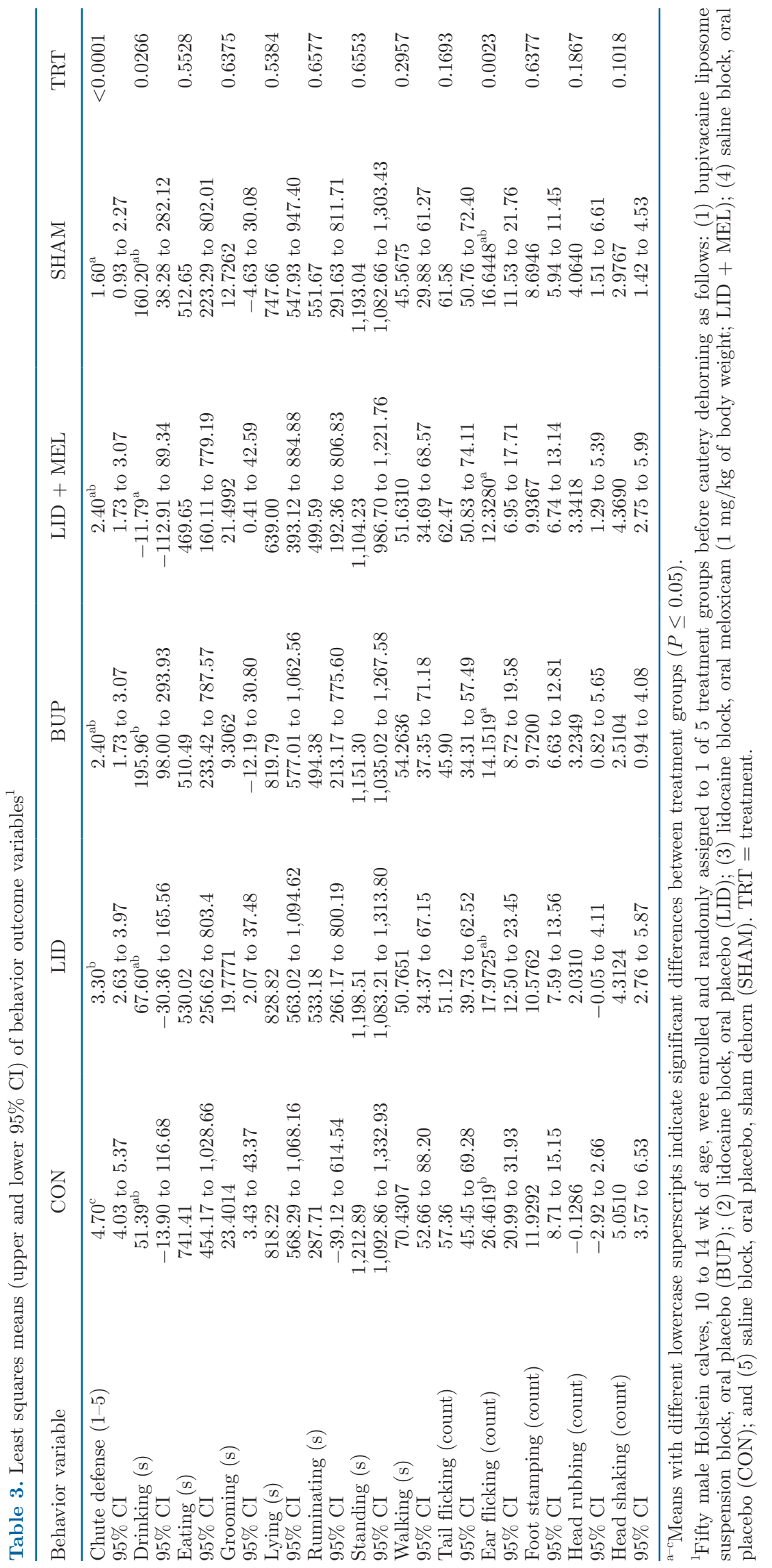




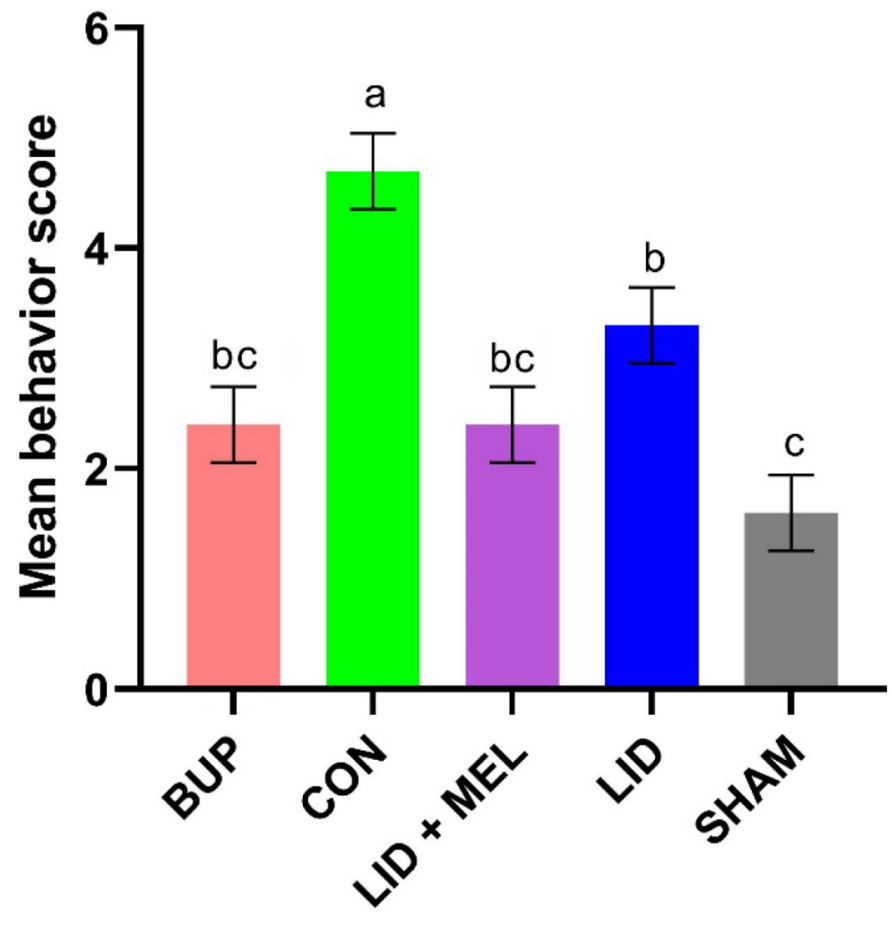

Figure 4. Mean chute defense behavior score (0-5), adapted from Grandin (1993) and Hoppe et al. (2010) at the time of dehorning for each of the 5 treatment groups. Error bars indicate SEM. Different letters $(\mathrm{a}-\mathrm{c})$ indicate significant differences between treatment groups $(P$ $\leq 0.05)$. BUP $=$ bupivacaine liposome suspension block, oral placebo; $\mathrm{CON}=$ saline block, oral placebo; LID + MEL = lidocaine block, ora meloxicam; LID = lidocaine block, oral placebo; SHAM = saline block, oral placebo, sham.

\section{DISCUSSION}

Calves in the present study were 10 to 14 wk of age, which is older than what is recommended by the National Dairy FARM Program Animal Care Reference Manual Version 4 that requires that calves be disbudded by 8 wk of age (National Milk Producers Federation, 2020). Results from the 2017 National Animal Health Monitoring Survey of cow-calf operations showed that only $44 \%$ of cow-calf operations dehorned horned calves before they left the operation, revealing that many horned animals have the potential to be dehorned after weaning (USDA-APHIS-NAHMS, 2020). The need for analgesic protocols appropriate for calves $>8 \mathrm{wk}$ of age exists, and the data from the current study is translatable for older beef and dairy calves.

Evidence from the current study indicated that cautery dehorning resulted in changes in MNT, gait analysis, chute defense behavior, activity levels, and pain behaviors. These results are consistent with previous findings that suggest that dehorning causes physiological, neuroendocrine, and behavioral changes, indicated by a stressful or painful response in cattle (Stafford and Mellor, 2011; Stock et al., 2013). Previous research reports changes in cortisol (Glynn et al., 2013), MNT (Heinrich et al., 2010), ocular temperature (Stewart et al., 2008), and pain behaviors (Heinrich et al., 2010) following dehorning.

In the current study, treatment effects were observed for MNT, gait distance, chute defense behavior, drinking and ear flicking behavior, and PGEM concentrations. Changes from baseline levels in MNT and gait analysis were observed throughout the duration of the study, indicating that calves may have experienced pain 120 $\mathrm{h}$ postcautery dehorning. Previous studies have shown that pressure sensitivity increased around the horn bud for at least $3 \mathrm{wk}$ following disbudding (Adcock and Tucker, 2018) and that calves experienced ongoing pain $3 \mathrm{wk}$ following disbudding (Adcock and Tucker, 2020). Wounds took between 52 and $72 \mathrm{~d}$ to re-epithelialize and were more painful than new epithelium throughout the healing process (Adcock and Tucker, 2018). The prolonged pain response for days following dehorning may be due to the nature of the injury. Burn injury from cautery dehorning causes excessive and prolonged edema, which can exacerbate pain and slow wound healing (Rowan et al., 2015).

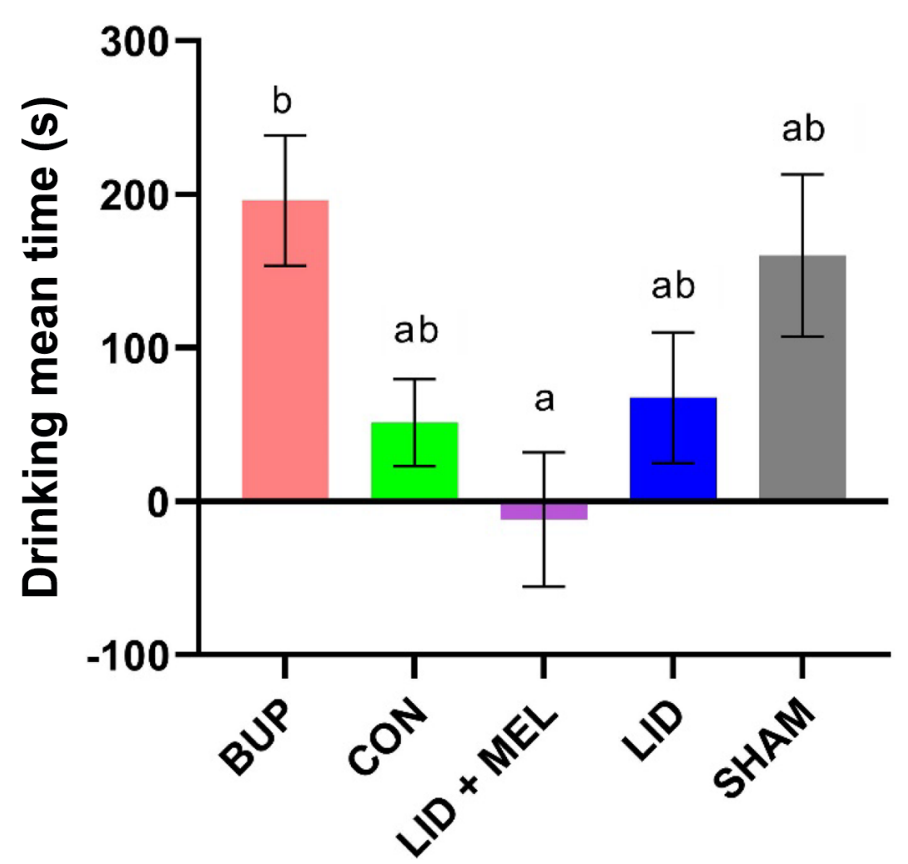

Figure 5. Drinking behavior expressed as mean time (s) for the duration of the study $(120 \mathrm{~h})$ for each of the 5 treatment groups. Error bars indicate SEM. Different letters $(\mathrm{a}, \mathrm{b})$ indicate significant differences between treatment groups $(P \leq 0.05)$. BUP $=$ bupivacaine liposome suspension block, oral placebo; $\mathrm{CON}=$ saline block, oral placebo; LID + MEL = lidocaine block, oral meloxicam; LID = lidocaine block, oral placebo; SHAM = saline block, oral placebo, sham. 
Ocular temperatures gradually increased for all treatment groups from 0 to $8 \mathrm{~h}$, with a sharp increase from $2 \mathrm{~h}$ to $8 \mathrm{~h}$ consistent with higher ambient temperatures midday. Environmental factors as well as distance from the animal can be very influential upon IRT readings (Church et al., 2014). The study investigators maintained the same distance from each calf and avoided capturing images in direct sunlight. Ocular temperatures for all treatment groups returned to baseline levels at $24 \mathrm{~h}$. These results are consistent with Stock et al. (2015), who also recorded a mean peak temperature at $8 \mathrm{~h}$. There was not a significant decrease in ocular temperature immediately following dehorning in any of the treatment groups. Previous studies have reported a decrease in ocular temperature during the $5 \mathrm{~min}$ following dehorning without use of a local anesthetic and between 2 and $3 \mathrm{~h}$ when a local anesthetic without an NSAID was administered (Stewart et al., 2008, 2009). The lack of an analgesic effect on ocular temperature may be indicative that ocular temperature changes are reflective of a stress response and are not solely accurate as a pain indicator (Glynn et al., 2013).

Mechanical nociceptive threshold measures decreased for all treatment groups throughout the current study,

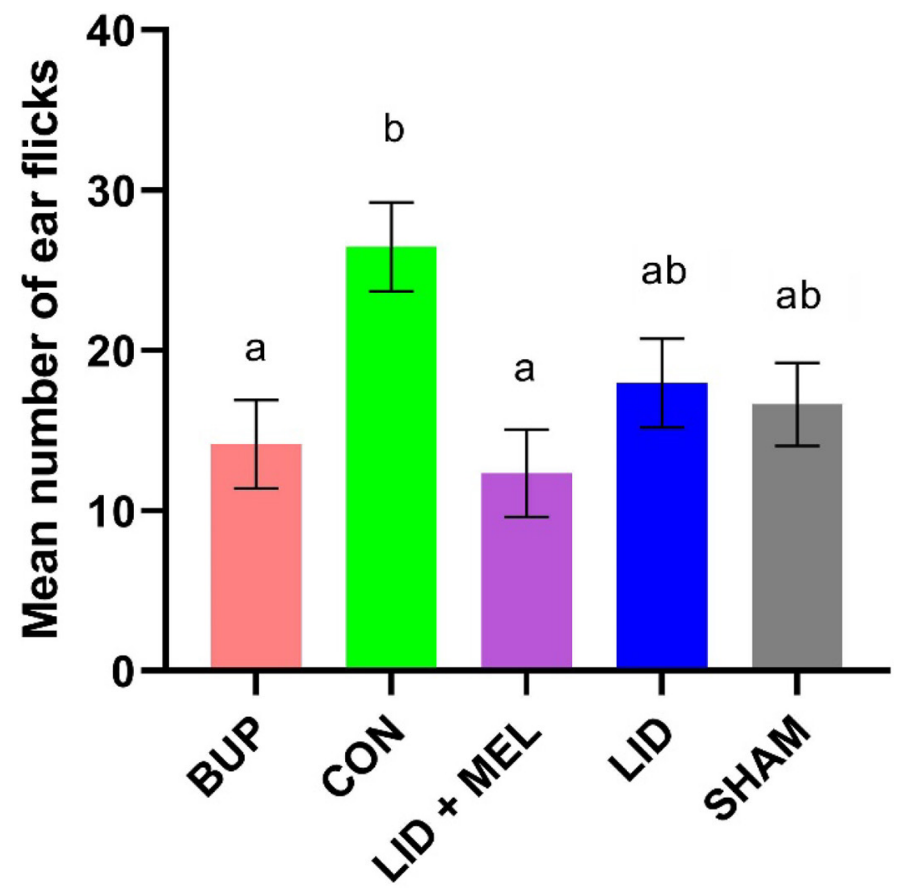

Figure 6. Ear flicking behavior expressed as a mean for the duration of the study $(120 \mathrm{~h})$ for each of the 5 treatment groups. Error bars indicate SEM. Different letters $(\mathrm{a}, \mathrm{b})$ indicate significant differences between treatment groups $(P \leq 0.05)$. BUP $=$ bupivacaine liposome suspension block, oral placebo; $\mathrm{CON}=$ saline block, oral placebo; LID $+\mathrm{MEL}=$ lidocaine block, oral meloxicam; LID = lidocaine block, oral placebo; SHAM = saline block, oral placebo, sham. with the sharpest decrease observed from 24 to $72 \mathrm{~h}$ for all treatment groups except SHAM. The SHAM group returned to baseline levels from 8 to $120 \mathrm{~h}$, indicating that calves on study did not become sensitized to MNT measurement. This also suggested that all dehorned treatment groups were still painful at the conclusion of the study period. Based on the MNT results, the BUP treatment seemed most effective, having the longest duration of pain control, with the CON and LID groups being most painful at 4 and $24 \mathrm{~h}$, respectively. Findings from previous research have shown that administration of meloxicam in addition to lidocaine results in calves being less sensitive to force at $24 \mathrm{~h}$ than calves only administered lidocaine (Allen et al., 2013). In the current study, at the end of the LID treatment duration, the LID group may have become more painful than the CON group due to the anesthetic blunting of the body's natural inflammatory response to injury during its duration of action (Stafford and Mellor, 2005). In a meta-analysis of previous disbudding studies, higher cortisol concentrations were seen at $4 \mathrm{~h}$ in calves receiving a local anesthetic relative to controls, corresponding to when the local anesthetic duration of action ended (Winder et al., 2018); this cortisol spike was not observed in the present study.

Pressure mat gait analysis uses a floor-based mat that records and analyzes the contact force, contact area, and stance time for each limb. Gait distance increased the most from baseline at $4 \mathrm{~h}$ and then gradually decreased out to $120 \mathrm{~h}$ but did not return to baseline levels by the conclusion of the study period. The longer gait distance in the CON, LID, and LID + MEL groups may be due to calves experiencing more pain at the dehorning site; consequently, calves changed their head position, which increased stride length. Mean stance time decreased from baseline levels at $4 \mathrm{~h}$ and remained shorter, not returning to baseline levels by the conclusion of the study period. Mean stride length increased from baseline levels at all time points except $24 \mathrm{~h}$. Mean force and mean contact pressure decreased steadily over time from baseline out to $120 \mathrm{~h}$. Gait analysis is a novel approach to evaluate pain in cattle. Recently, gait analysis was used to support the approval of a transdermal formulation of flunixin, which is the first analgesic compound labeled for cattle to control pain associated with foot rot in the United States (FDA, 2017). The pressure mat gait analysis has also been used to assess pain associated with lameness in cattle and swine, castration in cattle, and parturition in cattle (PairisGarcia et al., 2015; Kleinhenz et al., 2018; Kleinhenz et al., 2019). To our knowledge, this is the first study that has used gait analysis to assess pain associated with dehorning in calves. Additional studies are required to 


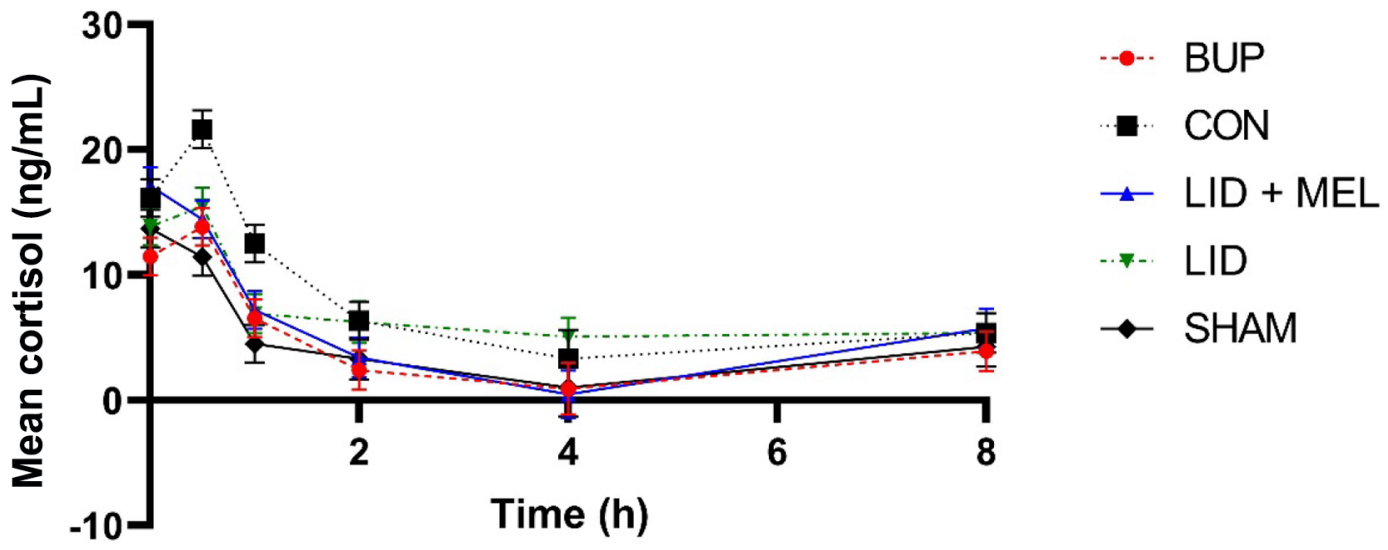

Figure 7. Mean cortisol concentrations measured in $\mathrm{ng} / \mathrm{mL}$ over the first $8 \mathrm{~h}$ of the study for each of the 5 treatment groups. No significant treatment differences were observed. Error bars indicate SEM. BUP = bupivacaine liposome suspension block, oral placebo; CON = saline block, oral placebo; LID + MEL = lidocaine block, oral meloxicam; LID = lidocaine block, oral placebo; SHAM = saline block, oral placebo, sham.

gain a better understanding of changes in gait and their association with pain following dehorning.

Mean scores for chute defense behavior differed between the CON group and all other treatment groups, suggesting that a local anesthetic alone reduced defensive behaviors at the time of the dehorning procedure. However, the LID group exhibited a higher chute defense score than the SHAM group, suggesting that lidocaine alone did not alleviate all pain associated with the dehorning procedure. Drinking was the only activity that indicated a treatment difference in the present study, with the BUP group spending more time drinking. Previous findings have suggested that meloxicam may increase quiescence, but that was not observed in the present study (Heinrich et al., 2010; Theurer et al.,
2012). Calves spent less time eating at 4, 8, and $24 \mathrm{~h}$ following dehorning compared with baseline levels, but eating behavior did increase from 4 to $24 \mathrm{~h}$. Calves may have been in pain and less motivated to eat the day of the dehorning procedure. However, calves were more motivated to eat by the first feeding period at 24 $\mathrm{h}$ postdehorning, but still had not returned to baseline levels. Collecting more data for a longer period of time would be valuable to see when calves returned to baseline levels for eating behavior. Theurer et al. (2012) found that calves only administered meloxicam spent more time eating on d 2 and 6 postdehorning compared with negative controls. Heinrich et al. (2010) did not find a significant difference in intake between calves administered lidocaine and meloxicam or lidocaine alone

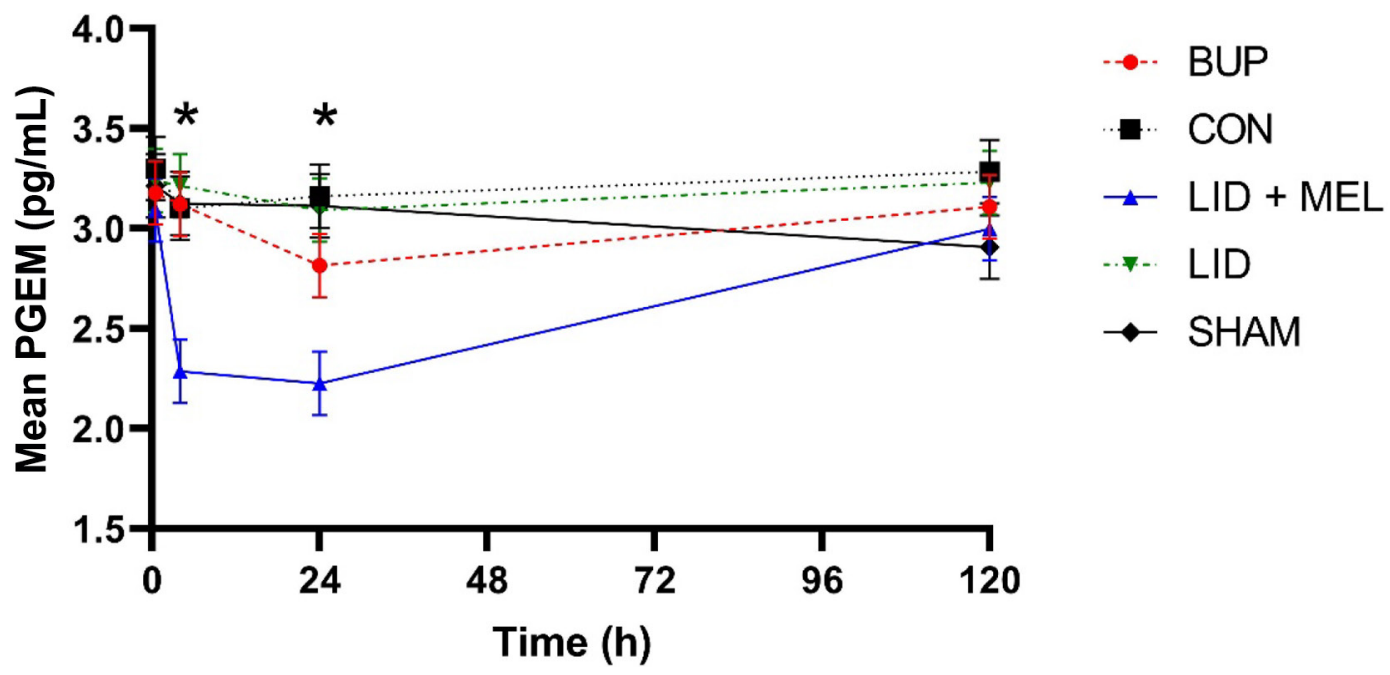

Figure 8. Mean prostaglandin $\mathrm{E}_{2}$ metabolite concentration measured in $\mathrm{pg} / \mathrm{mL}$ over the duration of the study for each of the 5 treatment groups. Error bars indicate SEM. *Denotes time points where a significant difference $(P \leq 0.05)$ was observed between at least 2 treatment groups. 
before dehorning. Ear flicking (defined as rapidly moves one or both ears to the front and back, independent of head shaking) results from the current study indicated that the BUP and LID + MEL treatment groups had reduced ear flicking relative to the CON group. The CON group mean did not differ from the SHAM group; however, the CON mean was numerically larger and the $95 \%$ confidence intervals overlapped, which may have been influenced by variation between individual animals. A larger sample size may have produced different results. In a meta-analysis of cautery disbudding studies, ear flicks at 1,6 , and $24 \mathrm{~h}$ were found to have great heterogeneity, but at 3 or $4 \mathrm{~h}$, less heterogeneity and a protective treatment effect was observed (Winder et al., 2018). Negative mean values were a result of calves being out of view of the video camera due to obstructions such as other animals, objects in the pen, and study personnel. Calves averaged being at least partially out of view for 24 to $57 \%$ from a single scoring period, which likely affected behavior results. Future studies may implement a more robust system to minimize the risk of calves being out of view of the camera.

Cortisol concentrations increased immediately following dehorning at 0 and $0.5 \mathrm{~h}$ but returned to baseline levels from 1 to $2 \mathrm{~h}$ following dehorning. Previous studies have characterized the acute cortisol response following dehorning (Heinrich et al., 2009; Stock et al., 2015). Cortisol is reported to be a good indicator of acute pain and distress, but showed no evidence of calves still in pain beyond $1 \mathrm{~h}$ following dehorning, which did not align with other outcome variables. Cortisol concentrations also did not appear to be sensitive to an analgesic effect. This is not consistent with McMeekan et al. (1998), who administered bupivacaine $20 \mathrm{~min}$ before dehorning and again a second time $4 \mathrm{~h}$ after the procedure and prevented a cortisol response for $8 \mathrm{~h}$; however, quantification methods and limits of detection have progressed since the cited study took place. Cortisol concentrations can be quite variable in response to a stressor, as well as calf age (Stock et al., 2013). In the current study, the cortisol response observed across treatment groups may be indicative of the stress of restraint despite acclimation. Furthermore, cautery dehorning may have destroyed the nociceptors adjacent to the wound and mitigated the cortisol response specific to pain (Stafford and Mellor, 2005).

The concentration of prostaglandin $\mathrm{E}_{2}$ metabolites only differed in calves treated with meloxicam, which is consistent with previous findings that suggest that NSAID reduce prostaglandin $\mathrm{E}_{2}$ concentrations over the duration of action of the drug (Stock et al., 2016). No differences were observed between CON and SHAM calves, which is also consistent with previous findings following dehorning (Stock et al., 2016). The cortisol spike immediately following the dehorning procedure could have potentially inhibited aspects of the inflammatory response and prevented a response in prostaglandin $\mathrm{E}_{2}$ metabolite concentration across treatment groups (Van Engen and Coetzee, 2018).

Lidocaine is the most widely used local anesthetic in veterinary practice in the United States, and its widespread use in dehorning procedures is likely attributable to its low cost and long shelf-life (Riviere and Papich, 2018). A multimodal approach of lidocaine and meloxicam has been well-characterized as a more effective option for controlling pain associated with cautery dehorning, with a longer duration of action than lidocaine alone (Heinrich et al., 2010). However, lidocaine use in food animals is no longer allowed in the European Union, demonstrating the need for investigation into alternative analgesic options. Bupivacaine liposome suspension is novel option for pain control during dehorning. Based on the results of the present study, the bupivacaine liposome suspension did not have a delayed onset relative to lidocaine, and it controlled pain for a duration similar to the combination of lidocaine and meloxicam. No drugs are currently labeled to control pain from dehorning in cattle in the United States, and thus extralabel drug use under the Animal Medicinal Drug Use Clarification Act is the only way this use is permitted (FDA, 1994). Producer ability to implement a change is key for adopting new means of pain control (Jansen et al., 2009), and bupivacaine liposome suspension is not readily available or likely cost-effective for producers to implement at the time of dehorning, currently. However, effective anesthesia for dehorning is becoming increasingly recognized as an industry requirement (Bates et al., 2019; National Milk Producers Federation, 2020), and thus the availability and cost of drugs may evolve with time. Although bupivacaine liposome suspension does not seem to provide any extended duration of analgesia relative to a multimodal approach of lidocaine and meloxicam, it may be more practical for producers to only administer 1 product. The need for analgesic options that control pain for an extended duration without the need for readministration and that are practical for producers to implement is apparent and still requires further investigation. To improve animal well-being in the future, the use of polled genetics is a viable alternative to causing pain from disbudding and dehorning procedures.

\section{CONCLUSIONS}

Evidence provided in the current study indicated that pain from cautery dehorning can last up to $120 \mathrm{~h}$ postdehorning, indicated by changes in nociception and gait analysis. These data show that a single administration 
of bupivacaine liposome suspension as a cornual block at the time of dehorning was as effective at controlling pain, as evidenced by nociceptive threshold and gait distance, as a multimodal approach of a lidocaine block and systemic meloxicam. A single injection that alleviates both perioperative and postoperative pain would be an attractive option for livestock producers to alleviate pain at the time of dehorning. Further research is needed to determine the repeatability of these results, to quantify pain in different age groups of calves, and to discover effective ways of managing pain for extended durations following painful husbandry procedures.

\section{ACKNOWLEDGMENTS}

This project was supported by the College of Veterinary Medicine at Kansas State University (Manhattan, KS). Author M. S. Martin is a Foundation for Food and Agriculture Research (FFAR) fellow. Authors M. D. Kleinhenz, A. V. Viscardi, and J. F. Coetzee are supported by the Agriculture and Food Research Initiative, competitive grant numbers 2017-67015-27124, 202067030-31479, 2020-67015-31540, 2020-67015-31546, and 2021-67015-34084 from the USDA National Institute of Food and Agriculture (Washington, DC). The authors have not stated any conflicts of interest.

\section{REFERENCES}

AABP. 2019. Dehorning Guidelines. American Association of Bovine Practitioners. Accessed Feb. 4, 2021. https://aabp.org/Resources/ AABP_Guidelines/Dehorning-2019.pdf.

Adcock, S. J., and C. B. Tucker. 2018. The effect of disbudding age on healing and pain sensitivity in dairy calves. J. Dairy Sci. 101:10361-10373. https://doi.org/10.3168/jds.2018-14987.

Adcock, S. J., and C. B. Tucker. 2020. Conditioned place preference reveals ongoing pain in calves 3 weeks after disbudding. Sci. Rep. 10:3849. https://doi.org/10.1038/s41598-020-60260-7.

Allen, K. A., J. Coetzee, L. Edwards-Callaway, H. Glynn, J. Dockweiler, B. KuKanich, H. Lin, C. Wang, E. Fraccaro, M. Jones, and L. Bergamasco. 2013. The effect of timing of oral meloxicam administration on physiological responses in calves after cautery dehorning with local anesthesia. J. Dairy Sci. 96:5194-5205. https://doi.org/ $10.3168 /$ jds.2012-6251.

AVMA. 2014. Welfare Implications of Dehorning and Disbudding Cattle. Accessed Feb. 4, 2021. https://www.avma.org/resources-tools/ literature-reviews/welfare-implications-dehorning-and-disbudding -cattle.

Bates, A. J., M. Sutherland, F. Chapple, S. Dowling, A. Johnson, B. Saldias, and J. Singh. 2019. A new method of administering local anesthesia for calf disbudding: Findings from a comparative onfarm study in New Zealand. J. Dairy Sci. 102:2492-2506. https:// doi.org/10.3168/jds.2018-15033.

Best, C. A., A. A. Best, T. J. Best, and D. A. Hamilton. 2015. Buffered lidocaine and bupivacaine mixture-the ideal local anesthetic solution? Plast. Surg. (Oakv.) 23:87-90. https://doi.org/10.1177/ 229255031502300206.

Church, J. S., P. Hegadoren, M. Paetkau, C. Miller, G. Regev-Shoshani, A. Schaefer, and K. Schwartzkopf-Genswein. 2014. Influence of environmental factors on infrared eye temperature measurements in cattle. Res. Vet. Sci. 96:220-226. https://doi.org/10.1016/j.rvsc 2013.11.006
Coetzee, J. F., B. KuKanich, R. Mosher, and P. Allen. 2009. Pharmacokinetics of intravenous and oral meloxicam in ruminant calves. Vet. Ther. 10:E1-E8.

Coetzee, J. F., R. A. Mosher, B. KuKanich, R. Gehring, B. Robert, J. Reinbold, and B. J. White. 2012. Pharmacokinetics and effect of intravenous meloxicam in weaned Holstein calves following scoop dehorning without local anesthesia. BMC Vet. Res. 8:153. https:/ /doi.org/10.1186/1746-6148-8-153.

Cozzi, G., F. Gottardo, M. Brscic, B. Contiero, N. Irrgang, U. Knierim, O. Pentelescu, J. Windig, L. Mirabito, and F. K. Eveillard. 2015. Dehorning of cattle in the EU Member States: A quantitative survey of the current practices. Livest. Sci. 179:4-11. https:// doi.org/10.1016/j.livsci.2015.05.011.

FASS. 2020. Guide for the Care and Use of Agricultural Animals in Research and Teaching. 4th ed. American Dairy Science Association, the American Society of Animal Science, and the Poultry Science Association.

Faulkner, P. M., and D. Weary. 2000. Reducing pain after dehorning in dairy calves. J. Dairy Sci. 83:2037-2041. https://doi.org/10.3168/ jds.S0022-0302(00)75084-3.

FDA. 1994. Animal Medicinal Drug Use Clarification Act of 1994 (AMDUCA). Accessed May 25, 2021. https://www.avma.org/KB Resources/Reference/Pages/AMDUCA.aspx.

FDA. 2016. FOI Original NADA 141-461 NOCITA bupivacaine liposome injectable suspension. Accessed Apr. 23, 2021. https:// animaldrugsatfda.fda.gov/adafda/app/search/public/document/ downloadFoi 947.

FDA. 2017. FOI NADA 141-450 Banamine Transdermal. Accessed Feb. 19, 2021. https://animaldrugsatfda.fda.gov/adafda/app/ search/public/document/downloadFoi/1944.

FDA. 2018. FOI Supplemental NADA 141-461 NOCITA bupivacaine liposome injectable suspension. Accessed Apr. 23, 2021. https:/ /animaldrugsatfda.fda.gov/adafda/app/search/public/document/ downloadFoi/3952.

Fulwider, W. K., T. Grandin, B. Rollin, T. Engle, N. Dalsted, and W. Lamm. 2008. Survey of dairy management practices on one hundred thirteen north central and northeastern United States dairies. J. Dairy Sci. 91:1686-1692. https://doi.org/10.3168/jds .2007-0631.

Glynn, H., J. Coetzee, L. Edwards-Callaway, J. Dockweiler, K. Allen, B. Lubbers, M. Jones, E. Fraccaro, L. Bergamasco, and B. KuKanich. 2013. The pharmacokinetics and effects of meloxicam, gabapentin, and flunixin in postweaning dairy calves following dehorning with local anesthesia. J. Vet. Pharmacol. Ther. 36:550561. https://doi.org/10.1111/jvp.12042.

Grandin, T. 1993. Behavioral agitation during handling of cattle is persistent over time. Appl. Anim. Behav. Sci. 36:1-9. https://doi .org/10.1016/0168-1591(93)90094-6.

Heinrich, A., T. Duffield, K. Lissemore, and S. Millman. 2010. The effect of meloxicam on behavior and pain sensitivity of dairy calves following cautery dehorning with a local anesthetic. J. Dairy Sci 93:2450-2457. https://doi.org/10.3168/jds.2009-2813.

Heinrich, A., T. Duffield, K. Lissemore, E. Squires, and S. Millman. 2009. The impact of meloxicam on postsurgical stress associated with cautery dehorning. J. Dairy Sci. 92:540-547. https://doi.org/ $10.3168 /$ jds.2008-1424.

Hoppe, S., H. Brandt, S. König, G. Erhardt, and M. Gauly. 2010. Temperament traits of beef calves measured under field conditions and their relationships to performance. J. Anim. Sci. 88:1982-1989. https://doi.org/10.2527/jas.2008-1557.

Jansen, J., B. Van den Borne, R. Renes, G. Van Schaik, T. Lam, and C. Leeuwis. 2009. Explaining mastitis incidence in Dutch dairy farming: The influence of farmers' attitudes and behaviour. Prev. Vet. Med. 92:210-223. https://doi.org/10.1016/j.prevetmed.2009 .08 .015 .

Johnstone, E. C., J. F. Coetzee, P. J. Pinedo, and L. Edwards-Callaway. 2021. Current attitudes of veterinarians and producers regarding the use of local and systemic analgesia in beef and dairy cattle in the United States. J. Am. Vet. Med. Assoc. 258:197-209. https://doi.org/10.2460/javma.258.2.197. 
Kleinhenz, M. D., N. Van Engen, P. Gorden, J. Ji, P. Walsh, and J. Coetzee. 2017. Effects of transdermal flunixin meglumine on pain biomarkers at dehorning in calves. J. Anim. Sci. 95:1993-2000. https://doi.org/10.2527/jas2016.1138.

Kleinhenz, M. D., N. Van Engen, J. Smith, P. Gorden, J. Ji, C. Wang, S. Perkins, and J. Coetzee. 2018. The impact of transdermal flunixin meglumine on biomarkers of pain in calves when administered at the time of surgical castration without local anesthesia. Livest. Sci. 212:1-6. https://doi.org/10.1016/j.livsci.2018.03.016.

Kleinhenz, M. D., P. J. Gorden, M. Burchard, J. A. Ydstie, and J. F. Coetzee. 2019. Rapid Communication: Use of pressure mat gait analysis in measuring pain following normal parturition in dairy cows. J. Anim. Sci. 97:846-850. https://doi.org/10.1093/jas/ sky 450.

McMeekan, C. M., D. Mellor, K. Stafford, R. Bruce, R. Ward, and N. Gregory. 1998. Effects of local anaesthesia of 4 to 8 hours duration on the acute cortisol response to scoop dehorning in calves. Aust. Vet. J. 76:281-285. https://doi.org/10.1111/j.1751-0813 .1998.tb10160.x.

Mellor, D. J., and K. Stafford. 2004. Animal welfare implications of neonatal mortality and morbidity in farm animals. Vet. J. 168:118 133. https://doi.org/10.1016/j.tvjl.2003.08.004.

National Milk Producers Federation. 2020. National Dairy FARM Program Animal Care Reference Manual Version 4. Accessed Sep. 18, 2021. https://nationaldairyfarm.com/wp-content/uploads/ 2020/09/FARM_Animal-Care-4-Manual_Layout_FINAL_091520 SinglePages.pdf.

Pairis-Garcia, M. D., A. Johnson, C. Abell, J. Coetzee, L. Karriker, S. Millman, and K. Stalder. 2015. Measuring the efficacy of flunixin meglumine and meloxicam for lame sows using a GAITFour pressure mat and an embedded microcomputer-based force plate system. J. Anim. Sci. 93:2100-2110. https://doi.org/10.2527/jas .2014-8796.

Riviere, J. E., and M. G. Papich. 2018. Veterinary Pharmacology and Therapeutics. 10th ed. John Wiley \& Sons.

Robles, I., A. G. Arruda, E. Nixon, E. Johnstone, B. Wagner, L. Edwards-Callaway, R. Baynes, J. Coetzee, and M. Pairis-Garcia. 2021. Producer and veterinarian perspectives towards pain management practices in the US cattle industry. Animals (Basel) 11:209. https://doi.org/10.3390/ani11010209.

Rowan, M. P., L. C. Cancio, E. A. Elster, D. M. Burmeister, L. F. Rose, S. Natesan, R. K. Chan, R. J. Christy, and K. K. Chung. 2015. Burn wound healing and treatment: Review and advancements. Crit. Care 19:243. https://doi.org/10.1186/s13054-015 $-0961-2$.

Smith, G. 2013. Extralabel use of anesthetic and analgesic compounds in cattle. Vet. Clin. North Am. Food Anim. Pract. 29:29-45. https: //doi.org/10.1016/j.cvfa.2012.11.003.

Stafford, K. J., and D. Mellor. 2005. Dehorning and disbudding distress and its alleviation in calves. Vet. J. 169:337-349. https://doi .org/10.1016/j.tvjl.2004.02.005.

Stafford, K. J., and D. J. Mellor. 2011. Addressing the pain associated with disbudding and dehorning in cattle. Appl. Anim. Behav. Sci. 135:226-231. https://doi.org/10.1016/j.applanim.2011.10.018.

Stewart, M., K. Stafford, S. Dowling, A. Schaefer, and J. Webster. 2008. Eye temperature and heart rate variability of calves disbudded with or without local anaesthetic. Physiol. Behav. 93:789-797. https://doi.org/10.1016/j.physbeh.2007.11.044.

Stewart, M., J. Stookey, K. Stafford, C. Tucker, A. Rogers, S. Dowling, G. Verkerk, A. Schaefer, and J. Webster. 2009. Effects of local anesthetic and a nonsteroidal antiinflammatory drug on pain responses of dairy calves to hot-iron dehorning. J. Dairy Sci. 92:1512-1519. https://doi.org/10.3168/jds.2008-1578.

Stock, M. L., S. L. Baldridge, D. Griffin, and J. F. Coetzee. 2013. Bovine dehorning: Assessing pain and providing analgesic manage- ment. Vet. Clin. North Am. Food Anim. Pract. 29:103-133. https: //doi.org/10.1016/j.cvfa.2012.11.001.

Stock, M. L., L. A. Barth, N. K. Van Engen, S. T. Millman, R. Gehring, C. Wang, E. A. Voris, L. W. Wulf, L. Labeur, W. H. Hsu, and J. F. Coetzee. 2016. Impact of carprofen administration on stress and nociception responses of calves to cautery dehorning. J. Anim. Sci. 94:542-555. https://doi.org/10.2527/jas.2015-9510.

Stock, M. L., S. T. Millman, L. A. Barth, N. K. Van Engen, W. H. Hsu, C. Wang, R. Gehring, R. L. Parsons, and J. F. Coetzee. 2015. The effects of firocoxib on cautery disbudding pain and stress responses in preweaned dairy calves. J. Dairy Sci. 98:6058-6069. https://doi.org/10.3168/jds.2014-8877.

Sutherland, M. A., M. Ballou, B. Davis, and T. Brooks. 2013. Effect of castration and dehorning singularly or combined on the behavior and physiology of Holstein calves. J. Anim. Sci. 91:935-942. https: //doi.org/10.2527/jas.2012-5190.

Theurer, M. E., B. J. White, J. F. Coetzee, L. N. Edwards, R. A. Mosher, and C. A. Cull. 2012. Assessment of behavioral changes associated with oral meloxicam administration at time of dehorning in calves using a remote triangulation device and accelerometers. BMC Vet. Res. 8:48. https://doi.org/10.1186/1746-6148-8-48.

Tong, Y. C. I., A. D. Kaye, and R. D. Urman. 2014. Liposomal bupivacaine and clinical outcomes. Baillieres. Best Pract. Res. Clin. Anaesthesiol. 28:15-27. https://doi.org/10.1016/j.bpa.2014.02.001.

USDA-APHIS-NAHMS. 2018. Health and Management Practices on U.S. Dairy Operations, 2014. Accessed May 23, 2021. https://www .aphis.usda.gov/animal_health/nahms/dairy/downloads/dairy14/ Dairy14_dr_PartIII.pdf.

USDA-APHIS-NAHMS. 2020. Beef Cow-calf Management Practices in the United States, 2017. Accessed Nov. 10, 2021. https://www .aphis.usda.gov/animal_health/nahms/beefcowcalf/downloads/ beef2017/Beef2017_dr_PartI.pdf.

Van Engen, N. K., and J. Coetzee. 2018. Effects of transportation on cattle health and production: A review. Anim. Health Res. Rev. 19:142-154. https://doi.org/10.1017/S1466252318000075.

Viñuela-Fernández, I., E. Jones, E. M. Welsh, and S. M. FleetwoodWalker. 2007. Pain mechanisms and their implication for the management of pain in farm and companion animals. Vet. J. 174:227239. https://doi.org/10.1016/j.tvj1.2007.02.002

Winder, C. B., S. J. LeBlanc, D. B. Haley, K. D. Lissemore, M. A. Godkin, and T. F. Duffield. 2016. Practices for the disbudding and dehorning of dairy calves by veterinarians and dairy producers in Ontario, Canada. J. Dairy Sci. 99:10161-10173. https://doi.org/10 .3168/jds.2016-11270.

Winder, C. B., C. L. Miltenburg, J. M. Sargeant, S. J. LeBlanc, D. B. Haley, K. D. Lissemore, M. A. Godkin, and T. F. Duffield. 2018. Effects of local anesthetic or systemic analgesia on pain associated with cautery disbudding in calves: A systematic review and metaanalysis. J. Dairy Sci. 101:5411-5427. https://doi.org/10.3168/jds .2017-14092.

\section{ORCIDS}

Miriam S. Martin (® https://orcid.org/0000-0002-4746-5011 Michael D. Kleinhenz (ํ) https://orcid.org/0000-0001-9453-3657 Andrew K. Curtis () https://orcid.org/0000-0002-3087-2841 Blaine T. Johnson ๑ https://orcid.org/0000-0002-9414-6515 Shawnee R. Montgomery (1) https://orcid.org/0000-0002-8194-397X Maria E. Lou (1) https://orcid.org/0000-0002-8962-0948 Johann F. Coetzee 누 https://orcid.org/0000-0003-1802-3991 